and children have to say about working mothers?

Don't look for the answers in this survey. The interviews were conducted with women only and the questions asked of them were cursory indeed.

That being said as it must, for a great opportunity has been lost, the survey has none the less compiled a fair amount of useful information. If there is still any prejudice against married women working, it is not held greatly by women themselves. Nearly one half of the married women surveyed were working; nearly one third were responsible for children of school age or younger, and even single women tended to have substantial domestic responsibilities. The birth of the first child, rather than marriage, now seems to be the main factor responsible for a woman's withdrawal from the labour force, but, once out, she tends to want to go back again.

To a surprising extent, working women did not have to pay someone to look after their children. Their husbands deputized a great deal (25.1 per cent of the under-twos whose mothers went out to work were cared for by their fathers) and their grandmothers helped even more. Nursery schools and day-care centres were not relied on very heavily. But they will clearly be needed in the future, as the next generation of grandmothers, accustomed to be at work, are less likely than the present house-bound generation to want to look after their daughters' children.

This survey consistently underestimates the pulling power of money. It emphasizes that although money was the biggest single attraction for getting married women out to work, the desire for company and relief from boredom were also powerful motives. It furthermore observes that non-working women believe that good companions, plus convenience to home, are what makes a job pleasant for a woman. The way to attract these women back to work, the survey concludes, is to meet these conditions. Yet with no mention of male earnings, the survey reports that women's pay on the average in 1965 was $5 s$. an hour and that only one in ninety earned as much as $10 \mathrm{~s}$. an hour. Surely the way to get women out of the home and into the labour force (when the present unemployment crisis subsides) is to offer them a healthy, rather than a derisory, reward for their efforts.

\section{Keele against Todd}

THe University of Keele is breathing defiance against the report of the Royal Commission on Medical Education under Lord Todd. The report, published last month, says that Keele is unlikely to become a suitable site for a new medical school, of which some four will need to be established in Britain over the next two decades. The university, whose plans to build a medical school date back to 1963 , has studied the report and now declares that it "will continue its all-out efforts to promote the establishment of a medical school at Keele at the earliest possible moment".

According to the Todd Report, a university which wishes to build a medical school must support flourishing faculties of biological sciences and have hospitals and a large population in its catchment area. The university should have at least 4,000 students in order to accommodate a minimum annual intake of 150 to 200 students at its medical school. Keele, it seems, does not fulfil these requirements, nor is it likely to. Its student population, 1,700 at present, will reach 2,000 in 1970 . Although strong on social sciences, the university does not possess faculties of physiology or biochemistry. The Todd commission suggests that Keele is "not on present plans likely" to be able to support a medical school that would be "economically and educationally effective". Only if its size and biological faculties increase should a school be built there.

Having studied these comments on its aspirations, Keele is now determined to set up the necessary ancillary faculties as well. The case for building a medical school at Keele rests on the presence of two large hospitals in the area, as well as an available site for development; furthermore, everybody at Keele is agreed that Keele is a suitable site. The fear is that the medical school may go to the University of Hull, about whose potentialities the Todd Report commented more favourably.

\section{Comparing A-Levels}

The way in which A-level examinations in England and Wales are set by a number of independent examining boards has often been a source of criticism. Anxious to iron out any differences in standards between the various GCE examining boards, the boards themselves have been trying since 1953 to pin down just what these differences might be. Various schemes of cross-marking have been tried, with examiners from one board marking the papers from another, but these rather subjective analyses highlighted only the most glaring differences. A deeper investigation is now under way into the comparability of A-level examinations, and results are expected in the autumn. The nine boards taking part cover Northern Ireland as well as England and Wales, but Scotland is not included because the Scots have no A-level examination as such. The idea is to give a series of tests to a number of candidates under each board, and to compare the results with the results of the normal A-level examinations set independently by the boards. 6,250 children from 389 schools were originally lined up for the tests, but final numbers will be slightly less because of last minute withdrawals and absences. After two years planning, the comparability tests will be taken this week, and results will be compared with the A-level papers to be taken next month.

The comparative tests consist of two papers on a common-core syllabus, one being a multiple choice paper and the other a conventional essay paper consisting of three compulsory questions. A third paper on similar lines to that used by the vice-chancellors' investigation (see Nature, 218, 410; 1968) will test aptitude. In addition, candidates will be asked to give some background details of previous examination results, interests and ideas for their careers. The results cannot be expected until the autumn, because the essay papers will be marked by A-level examiners who must first finish marking the A-level papers.

The examining boards concerned are contributing a total of $£ 16,000$ for the investigation, with the practical 